\title{
Diversity and genetic differentiation among subpopulations of Gliricidia sepium revealed by PCR-based assays
}

\author{
I. K. DAWSON*, A. J. SIMONS†, R. WAUGH \& W. POWELL \\ Scottish Crop Research Institute, Invergowrie, Dundee DD2 5DA and †Oxford Forestry Institute, South Parks Road, \\ Oxford OX1 3RB, U.K.
}

\begin{abstract}
Randomly amplified polymorphic DNA (RAPD), and a mitochondrial marker based on amplification of the V7 region of the mitochondrial small ribosomal RNA (srRNA) gene, were used to partition genetic variation within a single population of Gliricidia sepium sampled from Guatemala. Seventeen per cent of the variation detected with RAPDs was partitioned among subpopulations and indicated a greater level of discrimination than previously detected with isozymes. Cluster analysis indicated a direct relationship between this variation and the geographical distance between subpopulations. A polymorphism identified within the maternally inherited mitochondrial V7 srRNA product, which relied on digestion with restriction endonucleases, confirmed the genetic subdivision identified with RAPDs, and suggested a relatively limited role for seed in gene dispersal.
\end{abstract}

\section{Introduction}

The optimal collection and utilization of genetic resources from natural plant populations requires a detailed knowledge of the amount and distribution of genetic variability within and among those populations. Determinants of genetic structuring in plant populations include mating system (Loveless \& Hamrick, 1984; Ranker, 1992; Carthew, 1993 and references therein), natural (and possibly artificial) selection, evolutionary history, life-history characteristics and mechanisms of gene flow (Schaal, 1980; Ellstrand et al., 1989; Hamrick \& Godt, 1989; Hamrick et al., 1992; Philipp et al., 1992). Together, these factors can lead to complex genetic structuring within populations which is often difficult to resolve. The use of biochemical and molecular markers can enhance understanding of such complexities.

Currently, a variety of procedures able to reveal genetic variation within plant populations is employed. These include isozyme markers (Jana \& Pietzrak, 1988; Jelinski \& Cheliak, 1992), restriction fragment length polymorphisms (RFLPs) (Miller \& Tanksley, 1990; Wang et al., 1992) and methods based on the polymerase chain reaction (PCR) (Vosberg, 1989).

\footnotetext{
${ }^{*}$ Correspondence.
}

PCR is less technically demanding than RFLPs and requires only small amounts of DNA. In addition, PCR provides great flexibility in detecting genetic variation as a variety of primers can be used which are designed to reveal particular types of polymorphism (Rafalski \& Tingey, 1993), including microsatellites (Hughes \& Queller, 1993; Queller et al., 1993), endonuclease restriction of amplified products (Tragoonrung et al., 1992; Konieczny \& Ausubel, 1993), single-strand conformation polymorphisms (SSCPs) (Sheffield et al., 1993) and random amplified polymorphic DNA (RAPD) analysis (Williams et al., 1990). Unlike other approaches RAPD analysis requires no prior DNA sequence information as it relies on oligonucleotides of arbitrary sequence to prime the amplification of unspecified target DNAs. RAPDs therefore represent a PCR-based technology that is immediately applicable to organisms from diverse taxa and, because of the large number of primers available for analysis, potentially provides good overall genome coverage. Amplified polymorphic fragments are normally inherited in a biparental dominant Mendelian manner (Carlson et al., 1991; Roy et al., 1992; Rieseberg et al., 1993). RAPDs are of interest in several aspects of molecular ecology (Hadrys et al., 1992; Milligan \& McMurry, 1993). Huff et al. (1993) used RAPDs to differentiate natural populations of buffalograss (Buchloë dactyloides), Liu \& Furnier (1993) to discriminate between trembling 
aspen and bigtooth aspen (Populus tremuloides and $P$. grandidentata) and Puterka et al. (1993) to assess genetic relationships among collections of Russian wheat aphid (Diuraphis noxia).

Gliricidia sepium is a leguminous tree native to Meso-America, although it is now cultivated throughout the tropics (Hughes, 1987). In addition to having been directly influenced by humans through cultivation, the distribution of $G$. sepium has been greatly affected by clearance of tropical dry forest. Gliricidia can be an aggressive colonizer of cleared areas, which may lead to complex partitioning of variability within the species. $G$. sepium is used by rural communities to provide wood for fuel and construction, leaves for fodder and green manure and live trees to provide shade in plantations or to act as living fence posts. After Leucaena leucocephala, Gliricidia is believed to be the most widely cultivated tropical multipurpose tree and is currently undergoing intensive agronomic research because of its potential to enhance sustainable agricultural systems (Simons \& Dunsdon, 1992).

Gliricidia is an insect-pollinated obligate outbreeder (Simons \& Dunsdon, 1992), the primary pollinator of which is considered to be a species of carpenter bee, Xylocopa fimbriata (Janzen, 1983) that is capable of flight over a distance of several kilometres (A. J. Simons, unpublished data). The period from fertilization to seed maturity is between 35 and 60 days and at maturity pods dehisce explosively. Ejected seed can sometimes travel distances of over $25 \mathrm{~m}$.

Previous studies at the biochemical and molecular level on Gliricidia have involved chloroplast RFLPs (Lavin et al., 1991) and RAPD analysis (Chalmers et al., 1992) to assess genetic relationships within and among Gliricidia populations collected as bulked seed samples. In addition, genetic partitioning, both among populations and at various levels within populations collected as stratified samples, has been assessed with isozymes (Chamberlain, 1993).

Here we report the use of PCR to examine the distribution of genetic variation within a single population of $G$. sepium analysed in parallel with isozymes (Chamberlain, 1993). Two PCR-based techniques were employed: (i) RAPD analysis; and (ii) amplification of a portion of the mitochondrial genome in conjunction with restriction endonuclease digestion. This allowed (a) an assessment of the utility of RAPDs in discerning detailed population structure for Gliricidia; (b) tests of predictions regarding population structure; (c) a study of the relative role of pollen and seed in gene dispersal; and (d) provision of information relevant to the design of optimal collection strategies for Gliricidia.

\section{Materials and methods}

\section{Plant material and collection}

The population of $G$. sepium used in this study is located within the native range of Gliricidia, stretching approximately $40 \mathrm{~km}$ along a narrow $(1 \mathrm{~km})$ coastal strip in Guatemala, being isolated and bounded on its inland side by either mangrove swamp or cattle pasture. In 1991, seed was collected from four subpopulations included within this distribution, each approximately $8 \mathrm{~km}$ apart along the coast. Running northwest from Monterrico these are referred to as Monterrico, El Banco, Gariton and Puerto Viejo, which are names taken from the nearest local community. In the present study, 10 progeny from each of 20 trees, five trees from each of the four subpopulations, were used. Trees sampled from the same subpopulation were at least $50 \mathrm{~m}$ apart to reduce the chances of consanguinity. Progeny from individual trees (tree families) are likely to be half-sibs, although some may share the same paternal parent.

Material was grown from seed at SCRI, except for the Monterrico subpopulation, a part of which now constitutes a progeny trial in Honduras. Families and individuals were chosen at random and sampled directly from this site using silica gel to dry and preserve leaf material.

Genomic DNA was extracted from both fresh and dried leaves using a modification of the minipreparation method of Edwards et al. (1991).

\section{RAPD analysis}

PCR reactions involving arbitrary primers contained approximately $50 \mathrm{ng}$ of genomic DNA, $200 \mu \mathrm{M}$ each dATP, dCTP, dGTP and dTTP, 200 nм primer, $1 \times$ Taq polymerase buffer $\left(10 \mathrm{~mm}\right.$ Tris- $\mathrm{HCl}\left(\mathrm{pH} 8.8 ; 25^{\circ} \mathrm{C}\right), 50$ $\mathrm{mm}$ potassium chloride, $1.5 \mathrm{~mm}$ magnesium chloride, 0.1 per cent non-ionic detergent) and one unit Taq polymerase (Northumbria Biologicals) in a final volume of $50 \mu \mathrm{L}$. Each reaction was overlaid with 50 $\mu \mathrm{L}$ mineral oil. The thermal cycler was programmed for 45 cycles of $92^{\circ} \mathrm{C}$ for $1 \mathrm{~min}, 36^{\circ} \mathrm{C}$ for $2 \mathrm{~min}, 72^{\circ} \mathrm{C}$ for $2 \mathrm{~min}$, followed by a final extension step of $72^{\circ} \mathrm{C}$ for 5 min. Products were resolved on 2 per cent agarose gels.

Twenty-five arbitrary primers were screened for suitability on a small number of representative individuals. Primers varied in ability to detect polymorphism and in reproducibility. Seven primers which consistently revealed informative patterns over several independent PCR runs, on DNA extracted from both fresh and silica-dried leaf and over a range of DNA concentrations, were chosen for analysis of the entire 
population (Table 1). RAPDs were scored as presence (1) or absence (0) and $\chi^{2}$ analysis was used to test for independence between pairs of products amplified by the same primer.

\section{Mitochondrial DNA analysis}

The identification of a mitochondrial marker involved primers designed to flank the variable $\mathrm{V} 7$ region of the mitochondrial small ribosomal RNA (srRNA) gene (J. Russell, SCRI, personal communication; Neefs et al., 1990; Table 1). PCR was carried out as for random primers, except the annealing temperature was increased to $50^{\circ} \mathrm{C}$. In order to detect polymorphism, the product amplified initially from representative individuals was subject to digestion with a series of 10 restriction endonucleases (CfoI, HaeIII, HindIII, HinfI, HpaII, RsaI, Sau3AI, Sau96I, SinI and TaqI; Northumbria Biologicals) and resolved on 2 per cent agarose gels.

\section{Results}

\section{RAPD product distribution and analysis}

The seven arbitrary primers chosen for analysis revealed 27 polymorphic products that were consistently and unambiguously scorable in all tree families. Examples of the polymorphisms detected with three primers are given in Figs 1 and 2. RAPD product frequencies in tree families, subpopulations and the population as a whole are indicated in Table 2. Twelve products were polymorphic in each subpopulation and 15 only in certain subpopulations. Thirteen products were present at a frequency of less than 0.1 in the population. Locally common products were seen to be distributed throughout the population, with product SC10-35-G500 showing the most skewed distribution. Rare products showed a restricted distribution, with four such products restricted to single subpopulations.

Table 1 Primers used to assess intrapopulation variation in Gliricidia sepium

\begin{tabular}{ll}
\hline Primer & \multicolumn{1}{c}{ Sequence } \\
\hline SC10-30 & 5' CCGAACGGGT \\
SC10-35 & 5' GTGCGGACAG \\
SC10-39 & 5' GGACGGGTGC \\
SC10-50 & 5' ACGCGCTGGT \\
SC10-59 & 5' GCATGGAGCT \\
SC10-60 & 5' GGCCTTGAGT \\
SC10-99 & 5' CAGGGCCGCT \\
$\mathrm{mtV7}$ & 5' CTTTCATACAGGTGCTGC \\
$\mathrm{mtV7}$ & 5' TCACTGGCAGTCCCTCGT \\
\hline
\end{tabular}

Chi-squared analysis on pairs of products amplified by the same primer revealed only one highly significant association, that between SC10-60-G1900 and G2050 $(P<0.001)$. This value, combined with visual inspection of gels, indicated that unlike all other (dominant) products, SC10-60-G1900 and G2050 represented codominant products at the same locus.

Estimates of genetic diversity within tree families and subpopulations were obtained from Shannon's information index of $H_{\mathrm{o}}=-\Sigma p_{i} \ln p_{i}$ (Lewontin, 1973; Saghai-Maroof et al., 1984), where $p_{i}$ is the RAPD product frequency. $H_{\mathrm{o}}$ values were calculated on all polymorphic products and, additionally, on a restricted set of products which excluded those with a frequency of 1.0 in any individual tree family (Table 3 ). The latter estimate eliminates a portion of the error caused by the inability to identify hidden heterozygotes using RAPDs, the proportion of which may be particularly high for those loci which are polymorphic in the population but monomorphic in particular families. Products were considered as independent, except for SC10-60-G1900 and G2050, which were considered together to provide allele frequencies at a single locus.

$H_{\mathrm{o}}$ values based on all polymorphic products (Table 3 ) indicated Gariton and Puerto Viejo as the most diverse subpopulations $\left(H_{\mathrm{o}}\right.$ values of 0.295 and 0.286 , respectively) and Monterrico as the least diverse $\left(H_{\mathrm{o}}=0.198\right)$ subpopulation. Estimates based on the restricted set of products showed the same ranking of diversity estimates among subpopulations, except that Puerto Viejo $\left(H_{\mathrm{o}}=0.265\right)$ appeared significantly more diverse than Gariton $\left(H_{\mathrm{o}}=0.211\right)$. Partitioning this diversity within and among family, subpopulation and population components using Shannon's index on all polymorphic products (Table 4) indicated that, on average, 30 per cent of the variation was partitioned among tree families within subpopulations and 41 per cent among tree families within the total population. In addition, 17 per cent of the variation was partitioned among subpopulations in the population as a whole. Estimates of partitioning based on the restricted set of products (not shown) were not significantly different from those based on all polymorphisms. Similarity among subpopulations was represented by a dendrogram (Fig. 3) generated from cluster analysis of polymorphic product frequencies. Clustering of subpopulations reflected their geographical distribution, with the Puerto Viejo subpopulation being least similar to the other subpopulations.

\section{Detection of mitochondrial DNA polymorphism}

Amplification of the $\mathrm{V} 7$ region of the mitochondrial srRNA gene and separation on 2 per cent agarose gels 
Fig. 1 Amplification products generated using primer SC10-39 on 10 individuals from each of two tree families of Gliricida sepium taken from the Puerto Viejo subpopulation. Polymorphic products scored in this study are indicated with arrows.

Fig. 2 Amplification products generated from (a) primer SC10-30 and (b) primer SC10-60 on 10 individuals taken from Gliricidia sepium tree family 9 (Gariton). Products scored as polymorphic within this family are indicated with arrows. Tree family 9 is polymorphic for only five of 10 products scored as polymorphic in the total population using both primers SC10-30 and SC10-60. SC10-60G1900 and G2050 represent codominant products at the same locus. SC10-60-G2050 was scored on the basis of intensity differences.

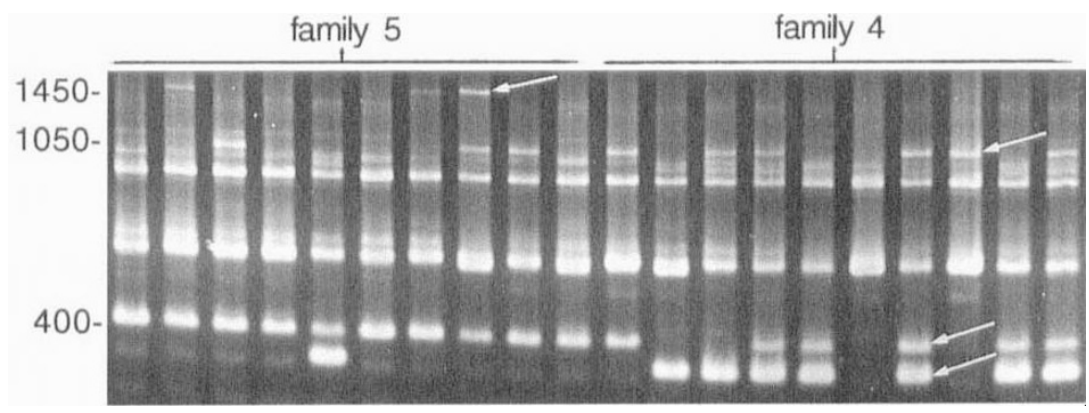

revealed a single product of approximately $530 \mathrm{bp}$ in a range of individuals. Subsequent screening with 10 restriction endonucleases indicated that a single enzyme, HaellI, was able to distinguish two mitochondrial genotypes, depending upon the presence or absence of a single cutting site. Subsequent amplification of mitochondrial DNA from pooled DNA samples constructed on a tree family basis, followed by HaeIII digestion (Fig. 4), indicated that product from all 150 individuals tested at the Monterrico, $\mathrm{El} \mathrm{Banco}$ and Gariton sites were of one mitochondrial genotype whereas all 50 individuals tested from the Puerto Viejo subpopulation were of the other genotype.

The mode of genetic inheritance of the mitochondrial polymorphism was tested in a sample of $F_{1}$ individuals $(n=7)$ derived from a cross of both parental genotypes. All $F_{1}$ individuals possessed only the maternal genotype.

\section{Discussion}

An understanding of the extent and distribution of genetic variation within Gliricidia populations is essential for devising sampling strategies which efficiently capture genetic diversity for selection trials and subsequent distribution of material to farmers that fulfils the dual aims of high genetic variation (which may provide an adaptive capacity to varying conditions) and reasonable performance.
The various statistics used to estimate and partition genetic variation at a detailed level within plant populations cannot be applied easily to RAPD data obtained from outcrossing species because of dominance. Codominant products are occasionally revealed (at one locus in the present study), but these are rare (Williams et al., 1990). Despite this, approximate estimators have been devised recently for various population-genetic parameters using RAPDs (Lynch \& Milligan, 1994), although these rely on an assumption of HardyWeinberg equilibrium. As individual Gliricidia half-sib families do not approach this equilibrium, further approximations regarding the inter-relationship of RAPD product frequency and underlying genetic variation are required and a relatively large sample of RAPDs must be scored to provide an effective description of population structure. In the present study, partitioning of genetic variation was based on RAPD product frequencies (except at the one locus revealing complete genotypic information) using Shannon's information measure. Shannon's analysis has general applications in ecology and is relatively insensitive to the skewing effects caused by the inability to detect heterozygous loci. In a second analysis a portion of the potentially large error in estimates of diversity, caused by the inability to identify hidden heterozygotes, was removed by excluding polymorphisms with a frequency of 1.0 in any tree family. Although this affected the relative estimates of genetic diversity of 


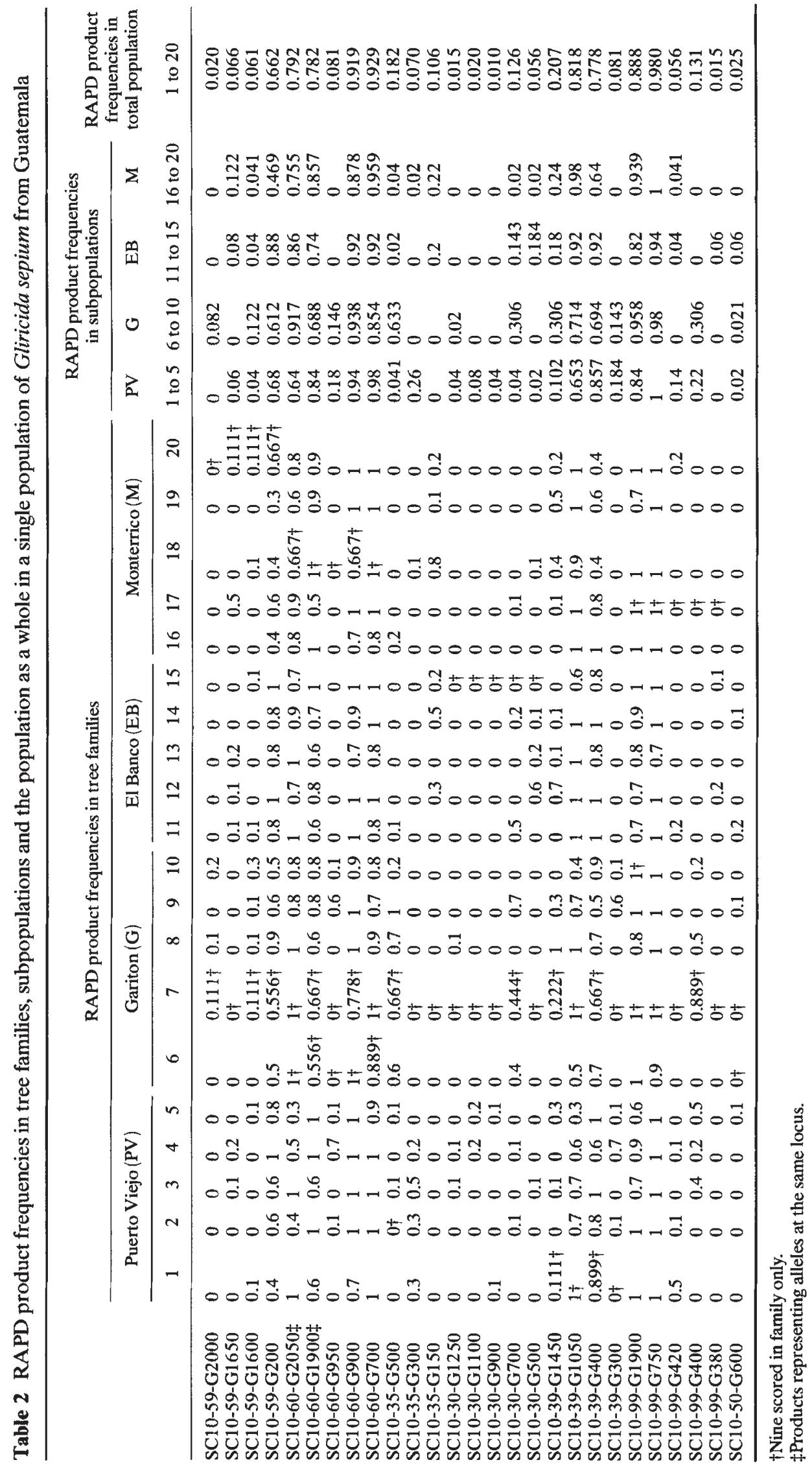


Table 3 Shannon's $H_{\mathrm{o}}$ values based on RAPDs for tree families, subpopulations and the population as a whole in a single population of Gliricida sepium from Guatemala

\begin{tabular}{|c|c|c|c|c|}
\hline & & & $H_{\mathrm{o}} \dagger$ & Average $H_{\mathrm{o}} \ddagger$ \\
\hline \multirow[t]{20}{*}{ Tree family } & Puerto Viejo & 1 & $0.175(0.150)$ & \\
\hline & & 2 & $0.161(0.142)$ & \\
\hline & & 3 & $0.211(0.173)$ & $0.207(0.187)$ \\
\hline & & 4 & $0.247(0.280)$ & \\
\hline & & 5 & $0.242(0.191)$ & \\
\hline & Gariton & 6 & $0.177(0.075)$ & \\
\hline & & 7 & $0.207(0.139)$ & \\
\hline & & 8 & $0.179(0.134)$ & $0.208(0.143)$ \\
\hline & & 9 & $0.250(0.194)$ & \\
\hline & & 10 & $0.229(0.174)$ & \\
\hline & El Banco & 11 & $0.188(0.174)$ & \\
\hline & & 12 & $0.155(0.164)$ & \\
\hline & & 13 & $0.198(0.095)$ & $0.162(0.137)$ \\
\hline & & 14 & $0.154(0.148)$ & \\
\hline & & 15 & $0.114(0.106)$ & \\
\hline & Monterrico & 16 & $0.114(0.040)$ & \\
\hline & & 17 & $0.121(0.096)$ & \\
\hline & & 18 & $0.196(0.124)$ & $0.146(0.091)$ \\
\hline & & 19 & $0.137(0.057)$ & \\
\hline & & 20 & $0.161(0.140)$ & \\
\hline \multirow[t]{4}{*}{ Subpopulation } & Puerto Viejo & $1-5$ & $0.286(0.265)$ & \\
\hline & Gariton & $6-10$ & $0.295(0.211)$ & \\
\hline & El Banco & $11-15$ & $0.227(0.185)$ & $0.252(0.198)$ \\
\hline & Monterrico & $16-20$ & $0.198(0.131)$ & \\
\hline Population & $1-20$ & & $0.295(0.238)$ & \\
\hline
\end{tabular}

Values outside parentheses are based on all polymorphic products. Values in parentheses exclude products with a frequency of 1.0 in any individual tree family (see Results for details).

†Mean value.

$\ddagger$ Mean diversity of families in a subpopulation or (bottom value) subpopulations in the population.

Table 4 Partitioning of genetic variation within and among families, subpopulations and the population as a whole in a single population of Gliricida sepium from Guatemala, according to Shannon's index

\begin{tabular}{|c|c|c|c|}
\hline Average values & & $\begin{array}{l}\text { Within group } \\
\text { component }\end{array}$ & $\begin{array}{l}\text { Among group } \\
\text { component }\end{array}$ \\
\hline \multirow[t]{5}{*}{ Families in subpopulations } & Puerto Viejo & 0.716 & 0.284 \\
\hline & Gariton & 0.696 & 0.304 \\
\hline & El Banco & 0.696 & 0.304 \\
\hline & Monterrico & 0.683 & 0.317 \\
\hline & Average & 0.698 & 0.302 \\
\hline Families in population & & 0.586 & 0.414 \\
\hline Subpopulations in population & & 0.834 & 0.166 \\
\hline
\end{tabular}


subpopulations it did not significantly alter the overall partitioning of variation.

In a group of randomly mating, outcrossing individuals the theoretical expectation for genetic partitioning within and among half-sib families is 75 per cent and 25 per cent, respectively (Hartl, 1987). Partitioning of genetic variation within and among tree families in subpopulations using Shannon's analysis indicates that, on average, 70 per cent of variation is distributed within and 30 per cent among tree families. Although the number of families used in the present study is relatively low (five per subpopulation), which limits the ability to estimate and partition diversity accurately, this average value suggests little deviation from random

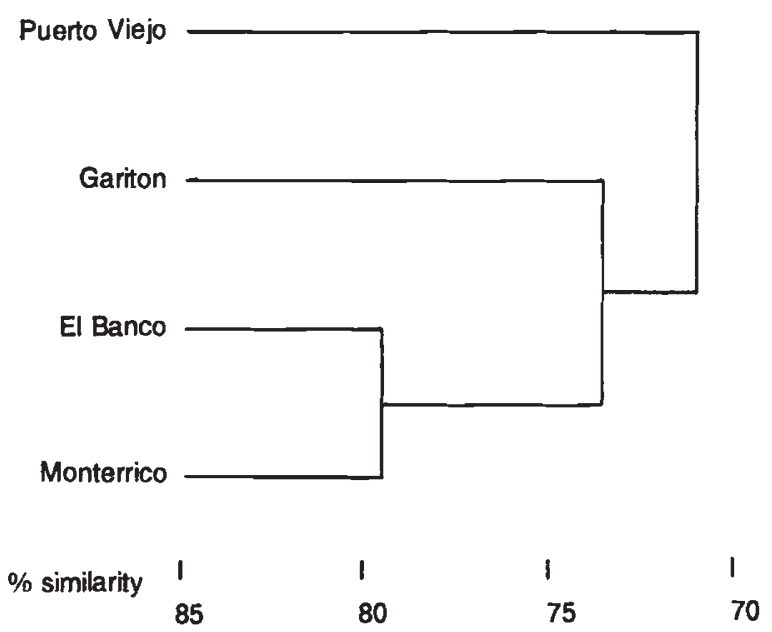

Fig. 3 Dendrogram based on RAPD similarities between four subpopulations taken from a single population of Gliricida sepium. mating within subpopulations. This may indicate that the robust self-incompatibility mechanism of Gliricidia, the explosive dehiscence of pods, the long distance foraging behaviour of the pollinator and an intolerance of genetic load (Simons \& Dunsdon, 1992) counters nonrandom pollen distribution and consanguineous mating at a subpopulation level. However, partitioning of diversity within and among tree families in the total population (values of 59 per cent and 41 per cent, respectively), or within and among subpopulations in the total population (values of 83 per cent and 17 per cent, respectively), indicates that a degree of genetic structuring exists among subpopulations. There is no appreciable difference in floral phenology between subpopulations which suggests that this is not a reason for structuring. Cluster analysis shows that differentiation appears to be clinal and indicates a relationship between geographical distance and genetic similarity based on RAPDs.

Parallel isozyme studies by Chamberlain (1993), with more extensive sampling of the same population of Gliricidia, suggest that subpopulations are close to equilibrium and indicate that there is only a small degree of differentiation between subpopulations (Wright's $F_{\mathrm{ST}}=0.058$ ). Direct comparisons between isozymes and RAPDs are difficult, however, because of a number of factors relating to information content and the different approaches used to screen, score and analyse polymorphisms. Seventeen per cent of variation detected with RAPDs partitions among the subpopulations, but this analysis excludes all monomorphic 'background' amplification products. Consequently, although this value indicates genetic structuring, it may be more of an indicator of the high discriminatory power available with RAPDs than an absolute measure

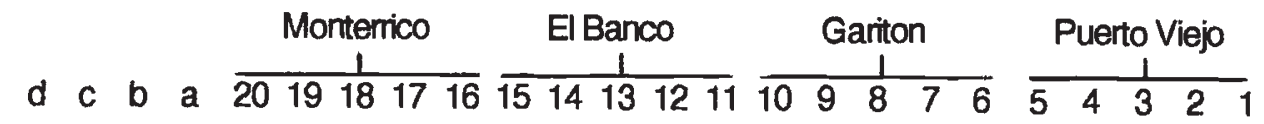

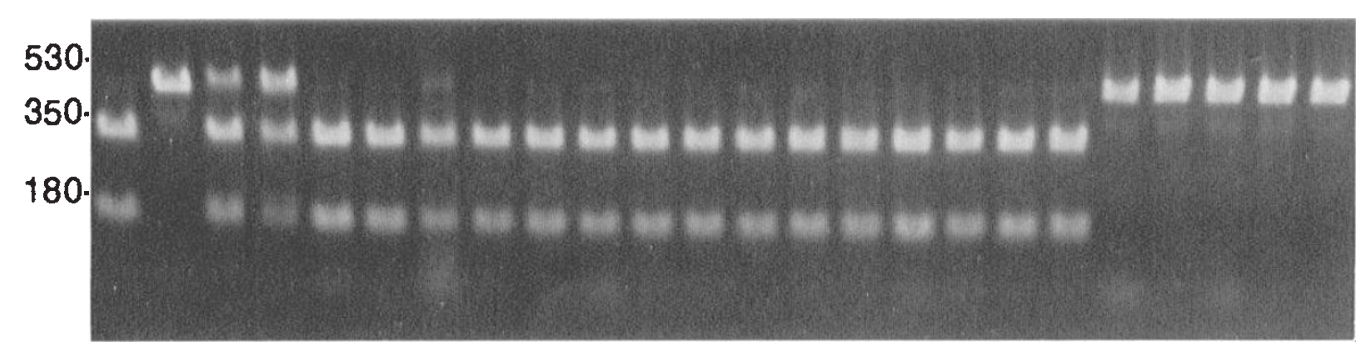

Fig. 4 Amplification products generated using primers to the V7 region of the mitochondrial srRNA gene combined with subsequent HaeIII digestion on 20 tree family pools of Gliricida sepium. Each pool contains 10 individuals from that family. Lanes (a) and (b) represent synthetic control pools containing three of 10 and one of 10 individuals (respectively) for which the mitochondrial product does not contain the HaeIII restriction site. Lanes (c) and (d) represent single individuals for which the V7 product does not contain and does contain (respectively) the HaeIII restriction site. 
of the proportion of within population differentiation. Other studies, comparing isozymes and RAPDs directly, indicate that both approaches reveal the same general pattern of variation, but that RAPDs provide greater overall resolution (e.g. Puterka et al., 1993 in Russian wheat aphid; Lui \& Furnier, 1993 in aspen). Although greater resolution must partly reflect the greater number of markers available via RAPDs, additional factors associated with RAPD dominance and relative phenotypic neutrality may also be involved. In particular, there is some evidence of non-neutrality at some isozyme loci (Karl \& Avise, 1992; but see also Watt, 1994). Whatever the source of greater RAPD discrimination, an increased understanding of detailed population structure is provided which is potentially relevant for the design of collection strategies to capture optimally genetic variation.

The identification of seed- or pollen-specific markers directly facilitates estimates of the relative contributions to gene flow made by pollen and seed. Arnold et al. (1991, 1992) used a combination of RAPDs or isozymes (nuclear markers) and chloroplast DNA (seed-specific marker) to identify insectmediated pollen transfer as the major mechanism of interspecific gene flow in Louisiana irises. Other studies on insect-mediated pollen transfer have involved pollen-specific isozyme markers to assess gene flow into natural and artificial populations of outcrossing species (e.g. Schaal, 1980; Ellstrand et al., 1989).

An understanding of gene flow mechanisms in Gliricidia is important because it influences the distribution of genetic variation within natural populations. In addition, mechanisms of gene flow have important implications for seed orchard design and genetic structuring between new introductions and pre-existing land races in exotic locations.

Although the maternal inheritance of the mitochondrial srRNA V7 product effectively reduces the number of individuals sampled at each subpopulation to five, the absolute subpopulation-specific distribution of genotypes contrasts with the distribution of RAPD products, none of which is identified as specifically diagnostic of all individuals within a particular subpopulation. This suggests a limited role for seed in gene dispersal compared with pollen transfer mediated by Xylocopa fimbriata which, although displaying a pattern of near-neighbour foraging (Simons \& Dunsdon, 1992), can fly distances of several kilometres. Caution should be taken in the extrapolation of these observations to other populations, however, since insect-mediated pollen flow can be idiosyncratic for particular environments or populations (Handel, 1983; Ellstrand et al., 1989). Interestingly, the subpopulation identified as unique by mitochondrial genotype (Puerto
Viejo) is also least similar to the other subpopulations based on cluster analysis of RAPDs. It is not known if these observations reflect any specific event in the evolutionary history of this population. Human-induced migration is thought to be minimal at this location and interviews with local people (A. J. Simons, unpublished data) indicate that this population is a remnant of a much larger population in existence up to 30-40 years ago, suggesting that the distribution of mitochondrial genotypes is not an artefact of cultivation. Observations made with chloroplast RFLPs (Lavin et al., 1991) also indicate that distinct organellar sublineages are contained within several populations of $G$. sepium, including the population described here.

In conclusion, this study demonstrates that RAPDs and PCR-based seed-specific markers may be used to assess and delineate patterns of genetic variation within G. sepium populations. Within the population studied here, RAPDs indicate a significant degree of geographically related differentiation among subpopulations, which suggests that stratified sampling may be necessary to capture effectively most genetic variation. The degree of subpopulation discrimination available with RAPDs is greater than that associated with isozymes, so that RAPDs may provide a more useful tool than isozymes in the design of collection strategies which retain more of the variation contained within populations.

\section{References}

ARNOLD, M. L., BUCKNER, C. M. AND Robinson, J, J. 1991. Pollenmediated introgression and hybrid speciation in Louisiana irises. Proc. Natl. Acad. Sci. U.S.A., 88, 1398-1402.

ARNOLD, M. L., ROBINSON, J. J., BUCKNER, C. M. AND BENNETT, B. D. 1992. Pollen dispersal and interspecific gene flow in Louisiana irises. Heredity, 68, 399-404.

CARLSON, J. E., TUlSiERAM, L. K., GLAUBiTZ, J. C., LUK, V. W. K., KAUfFELDT, C. AND RUTLEDGE, R. 1991. Segregation of random amplified DNA markers in $\mathrm{F}_{1}$ progeny of conifers. Theor. Appl. Genet., 83, 194-200.

CARTHEW, S. M. 1993. Population genetic structure of Banksia spinulosa. Heredity, 70, 566-573.

CHALMERS, K. J., WAUGH, R., SPRENT, J. I., SIMONS, A. J. AND POWELL, w. 1992. Detection of genetic variation between and within populations of Gliricidia sepium and $G$. maculata using RAPD markers. Heredity, 69, 465-472.

Chamberlain, J. 1993. Genetical and Geographical Variation in the Tropical Shrubs Gliricidia and Leucaena. Ph.D. Thesis, University of Cambridge, UK.

EDWARDS, K., JOHNSTONE, C. AND THOMPSON, c. 1991. A simple and rapid method for the preparation of plant genomic DNA for PCR analysis. Nucl. Acids Res., 19, 1349.

ELLSTRAND, N. C., DEVLIN, B. AND MARSHALl, D. L. 1989. Gene flow by pollen into small populations: data from experimental and natural stands of wild radish. Proc. Natl. Acad. Sci. U.S.A., 86, 9044-9047. 
HADRYS, H., BALICK, M. AND SCHIERWATER, B. 1992. Applications of random amplified polymorphic DNA (RAPD) in molecular ecology. Mol. Ecol., 1, 55-63.

HAMRICK, J. L. AND GODT, M. J. 1989. Allozyme diversity in plant species. In: Brown, A. H. D., Clegg, M. T., Kahler, A. L. and Weir, B. S. (eds) Population Genetics and Germplasm Resources in Crop Improvement, pp. 43-63. Sinauer Associates, Sunderland, MA.

HAMRICK, J. L. GODT, M. J. AND SHERMAN-BROYLES, S. L. 1992. Factors influencing levels of genetic diversity in woody plant species. New Forests, 6, 95-124.

HANDEL, S. N. 1983. Pollination ecology, plant population structure, and gene flow. In: Real, L. (ed.) Pollination Biology, pp. 163-211. Academic Press, Orlando, FL.

haRTL, D. L. 1987. A Primer of Population Genetics. Sinauer Associates, Sunderland, MA.

HUFF, D. R., PEAKALL, R., SMOUSE, P. E. 1993. RAPD variation within and among natural populations of outcrossing buffalograss [Buchlö̈ dactyloides (Nutt.) Engelm.]. Theor. Appl. Genet., 86, 927-934.

HUGHES, C. E. 1987. Biological considerations in designing a seed collection strategy for Gliricidia sepium (Jacq.) Walp. (Leguminosae). Commonwealth Forestry Rev., 66, 31-48.

HUGHES, C. R. AND QUELLER, D. C. 1993. Detection of highly polymorphic microsatellite loci in a species with little allozyme polymorphism. Mol. Ecol., 2, 131-137.

JANA, S. AND PIETRZAK, L. N. 1988. Comparative assessment of genetic diversity in wild and primitive cultivated barley in a center of diversity. Genetics, 119, 981-990.

JANZEN, D. H. 1983. Costa Rican Natural History. University of Chicago Press, Chicago.

JELSINKI, D. E. AND CHELIAK, w. M. 1992. Genetic diversity and spatial subdivision of Populus tremuloides (Salicaceae) in a heterogeneous landscape. Am. J. Bot., 79, 728-736.

KARL, S. A. AND AVISE, J. C. 1992. Balancing selection at allozyme loci in oysters: implications from nuclear RFLPs. Science, 256, 100-102.

KONIECZNY, A. AND AUSUBEL, F. M. 1993. A procedure for mapping Arabidopsis mutations using co-dominant ecotype-specific PCR-based markers. Plant J., 4, 403-410.

LAVIN, M., MATHEWS, S. AND HUGHES, C. 1991. Chloroplast DNA variation in Gliricidia sepium (Leguminosae): intraspecific phylogeny and tokogeny. Am. J. Bot., 78, 1576-1585.

LEWONTIN, R. C. 1973. The apportionment of human diversity. Evol. Biol., 6, 381-398.

LIU, z. AND FURNIER, G. R. 1993. Comparison of allozyme, RFLP, and RAPD markers for revealing genetic variation within and between trembling aspen and bigtooth aspen. Theor. Appl. Genet., 87, 97-105.

LOVELESS, M. D. AND HAMRICK, J. L. 1984. Ecological determinants of genetic structure in plant populations. Ann. Rev. Ecol. Syst., 15, 65-95.

LYNCH, M. AND MiLligAN, B. G. 1994. Analysis of population genetic structure with RAPD markers. Mol. Ecol., 3, 91-99.

MILLER, J. C. AND TANKSLEY, S. D, 1990. RFLP analysis of phylogenetic relationships and genetic variation in the genus Lycopersicon. Theor. Appl. Genet., 80, 437-448.
MiLligAN, B. G. AND McMURRY, C. K. 1993. Dominant vs. codominant genetic markers in the estimation of male mating success. Mol. Ecol., 2, 275-283.

NEEFS, J., VAN DE PEER, Y., HENDRIKS, L. AND DE WACHTER, R. 1990. Compilation of small ribosomal subunit RNA sequences. Nucl. Acids Res., 18, (Suppl.), 2237-2317.

PHILIPP, M., MADSEN, H. E. S. AND SIEGISMUND, H. R. 1992. Gene flow and population structure in Armeria maritima. Heredity, 69, 32-42.

PUTERKA, G. J., BLACK, W. C. IV, STEINER, W. M. AND BURTON, R. L. 1993. Genetic variation and phylogenetic relationships among worldwide collections of the Russian wheat aphid, Diuraphis noxia (Mordvilko), inferred from allozyme and RAPD-PCR markers. Heredity, 70, 604-618.

QUElleR, D. C., STRAsSmanN, J. E. AND Hughes, C. R. 1993. Microsatellites and kinship. Trends Ecol. Evol., 8, 285-288.

RAFALSKI, J. A. AND TINGEY, s. v. 1993. Genetic diagnostics in plant breeding: RAPDs, microsatellites and machines. Trends Genet., 9, 275-280.

RANKER, T. A. 1992. Genetic diversity, mating systems, and interpopulation gene flow in neotropical Hemionitis palmata L. (Adiantaceae). Heredity, 69, 175-183.

RIESEBERG, L. H., CHOI, H., CHAN, R. AND SPORE, C. 1993. Genomic map of a diploid hybrid species. Heredity, 70, 285-293.

ROY, A., FRASCARIA, N., MACKAY, J. AND BOUSQUET, J. 1992. Segregating random amplified polymorphic DNAs (RAPDs) in Betula allegheniensis. Theor. Appl. Genet., 85, 173-180.

SAGHAI-MAROOF, M. A., SOLIMAN, K. M., JORGENSEN, R. AND ALLARD, R. W. 1984. Ribosomal-DNA spacer-length polymorphisms in barley: Mendelian inheritance, chromosomal location, and population dynamics. Proc. Natl. Acad. Sci. U.S.A., 81, 8014-8018.

SCHAAL, B. A. 1980. Measurement of gene flow in Lupinus texensis. Nature, 284, 450-451.

SHEFFIELD, v. C., BECK, J, S., KWITEK, A. E., SANDSTROM, D. W. AND STONE, E. M. 1993. The sensitivity of single-strand conformation polymorphism analysis for the detection of single base substitutions. Genomics, 16, 325-332.

SIMONS, A. J. AND DUNSDON, A. J. 1992. Evaluation of the potential for genetic improvement of Gliricidia sepium. $O D A$ Forestry Research Project R4525 Final Report. Oxford Forestry Institute, Oxford.

TRAGOONRUNG, S., KANAZIN, V., HAYES, P. M. AND BLAKE, T. K. 1992. Sequence-tagged site-facilitated PCR for barley genome mapping. Theor. Appl. Genet., 84, 1002-1008.

VOSBERG, H.-P. 1989. The polymerase chain reaction: an improved method for the analysis of nucleic acids. Hum. Genet., 83, 1-15.

WANG, Z. Y., SECOND, G. AND TANKSLEY, S. D. 1992. Polymorphism and phylogenetic relationships among species in the genus Oryza as determined by analysis of nuclear RFLPs. Theor. Appl. Genet., 83, 565-581.

WATT, w. B. 1994. Allozymes in evolutionary genetics: selfimposed burden or extraordinary tool? Genetics, 136, 11-16.

WILLIAMS, J. G. K., KUBELIK, A. R., LIVAK, K. J., RAFALSKI, J. A. AND TINGEY, S. v. 1990. DNA polymorphisms amplified by arbitrary primers are useful as genetic markers. $\mathrm{Nucl}$. Acids. Res., 18, 6531-6535. 